\title{
Generations and Gender Survey study profile
}

\section{Anne Gauthier}

Susana Cabaço

cabaco@nidi.nl

Tom Emery

\author{
Netherlands Interdisciplinary Demographic Institute and University of Groningen, \\ the Netherlands \\ Netherlands Interdisciplinary Demographic Institute, the Netherlands
}

Netherlands Interdisciplinary Demographic Institute and Erasmus

University Rotterdam, the Netherlands

(Received January $2018 \quad$ Revised September 2018)

http://dx.doi.org/10.14301/llcs.v9i4.500

\begin{abstract}
The Generations and Gender Survey (GGS) is a panel study on families, life course trajectories and gender relations. The GGS is part of the Generations and Gender Programme (GGP), a unique research infrastructure providing open access data to registered researchers. We will be focusing on the GGS waves that were already collected. With large samples per country, the GGS microdata provides researchers with a key resource to examine changes in family life, inter-generational and gender relations. The analysis of these trends is at the core of the research produced in several social science disciplines and the GGS data users have extensively used it to better understand topics such as the transition to adulthood, partnership formation and dissolution, fertility, gender roles and caring responsibilities. In the first part of this study profile, we focus on the design features of the GGS (data collection and adjustment, panel maintenance, and coverage) and subsequently we provide an overview of the organisational setup and outputs of the GGP. In the last part we reflect on the opportunities and challenges ahead of the next round of data collection.
\end{abstract}

\section{Keywords}

Panel microdata; cross-national survey; family dynamics; life course trajectories; inter-generational relations

\section{Introduction}

The GGS is a cross-national longitudinal survey that provides open access data for researchers on a broad array of topics including partnerships, fertility, work-life balance, gender relations, transition to adulthood, intergenerational exchanges, care and later life. The GGS is a central part of the Generations and Gender Programme, a social science research infrastructure initiated in 2001. The Fertility and Families Survey (FFS) is the predecessor of the GGS and was conducted in the 1990s in 23 member states of the United Nations Economic Commission for Europe (UNECE).

The GGS is an individual-level fixed panel - it collects data from the same persons on multiple occasions. It is not a household or multiple generation within families panel. As of June 2018, it covers 25 countries. Out of these, the following 21 countries carried out a full GGS or survey that is closely comparable: Australia ${ }^{1}$, Austria, Belarus², Belgium, Bulgaria, Czech Republic, Estonia, France, Georgia, Germany, Hungary, Italy ${ }^{3}$, Japan ${ }^{4}$, Kazakhstan ${ }^{5}$, Lithuania, the Netherlands ${ }^{6}$, Norway, Poland, Romania, Russian Federation, Sweden. In addition, data from Spain, United Kingdom, United States and Uruguay have contributed to the Harmonized Histories collection.

The Harmonized Histories data file was created by the Non-Marital Childbearing Network (http://www.nonmarital.org/). It harmonises childbearing and marital histories from GGP 
countries with data from Spain, United Kingdom, United States and Uruguay - ensuring the data is ready for use in event history analysis.

An important issue to note is that in the first round of data collection the fieldwork implementation was co-ordinated nationally, which contributed to some discrepancies in the start dates of fieldwork, with wave 1 fieldwork extending from 2002-03 until 2012 (see table 1 below). The new round of data collection, starting in early 2020 , will be based on a fresh sample of respondents in each country and, to a large extent, the fieldwork implementation will be co-ordinated centrally, allowing for a more aligned (and narrower) chronological fieldwork window.

The GGP was developed to allow researchers to investigate and understand the changing family relations and intergenerational dynamics that have been part of deep demographic transformations in recent years. In addition, the survey includes a longitudinal component that enables the examination of the causes and consequences of behaviours and life events. The GGP is unique in its significant coverage of Central and East European countries and is also the only comparative panel study that covers the core adult age range (from age 18 to 79) (Gauthier and Emery, 2014).

In recent decades, studies based on the GGS have contributed to advancing knowledge about the factors that have been affecting family and life course dynamics and has generated key insights for policymakers. Our main aim in this paper is to provide an overview of the GGS, presenting its main features, from the design to data dissemination, including the background and characteristics of this unique data resource.

We start by focusing on aspects of the design of the GGS, including its main sampling characteristics and data collection methods. Next, we turn to the procedures used to minimise attrition, as well as data adjustment measures and scope of the thematic coverage of the GGS. The last sections will concentrate on organisational aspects (funding, management), outputs and evaluation of the main strengths and weaknesses of the GGS.

\section{Design}

The GGS data has been used to investigate partnership dynamics, transition to adulthood, fertility, care and support networks, division of household tasks, and contraception, among other topics. These data are an essential resource in the understanding of fundamental societal challenges across Europe and beyond and form a substantial basis for the formulation of evidence-based policies. The GGS is designed as a three-wave panel with three-year intervals between waves. This longitudinal design is of crucial importance for researchers who are interested in exploring the causes and consequences behind key societal questions. In addition, the longitudinal design enables researchers to explore the timing, frequency and duration of events or circumstances.

The sampling guidelines, summarised by Simard and Franklin (2005), specify three central elements: the target population is the resident noninstitutionalised population aged 18-79 (at the time of the first wave); the sample size of wave 1 should be sufficiently high to achieve at least 8,000 interviews in the event of a 3rd wave; and the use of probability sampling is required. It should be noted that the large sample sizes in each wave are one of the distinguishing features of the GGS and this allows data users to study, for example, specific social groups (low-income families) or particular family types. In addition, the broad age range further contributes to opening up new research possibilities in terms of the analysis of intergenerational relations and support.

Given that the GGS is a cross-national survey, the sampling frames were drawn at the national level, in line with country-specific characteristics and adopting the best available resources to define the sampling framework. Three main types of frames were used so far: population registers with names as samplings elements (Austria, Belgium, Italy, Norway and Sweden); area sampling with addresses or dwellings as sampling elements ${ }^{7}$ (Austria, Czech Republic, Germany, Hungary, Lithuania, the Netherlands, Romania, Russian Federation); and a combination of area and census information with names or dwellings as sampling elements (Bulgaria, Estonia, France, Georgia and Poland) (Fokkema, Kveder, Hiekel, Emery, \& Liefbroer, 2016). A detailed description of the sampling procedures and further documentation can be found via the GGP NESSTAR webpage (under 'Metadata' for each country). Also, the GGS metadata complies with the Data Documentation Initiative (DDI) standard, including information on sampling, questionnaire and codebooks (in the 'Study description' field, users can find information 
about the distributors, keywords, abstract, and guidelines on bibliographic citation).

In Germany, the study included a Turkish subsample. For data users, the over-sampling of subpopulations is very important to facilitate quantitative research on minorities, which enables the comparative analysis of groups with different backgrounds. For example, Wolf (2014) used this data to study the fertility behaviour of Turkish migrants in Germany and concluded that it is strongly associated with migration history (age at migration and duration of stay).

In terms of response rates in GGS wave 1 , the average response rate was $56 \%$. However, four countries had relatively low response rates Belgium, Lithuania, the Netherlands, and the Russian Federation - due to the inability to contact the individuals and their unwillingness to cooperate (Fokkema et al., 2016).

Some national teams - Australia, Austria, Germany, Hungary, the Netherlands, Norway, Russian Federation - also opted to use incentives to stimulate respondent participation in the survey. The incentives were either provided as cash, voucher or lottery ticket. In the Panel Maintenance section, we will explore attrition and measures adopted try to reduce nonresponse and to stimulate survey participation.

\section{Data collection}

In the first wave of the GGP, data collection was conducted by national teams, usually composed by national statistical offices and/or national research institutes. To facilitate the alignment of the fieldwork procedures, data collection guidelines were provided to each national team. One good example of this is the implementation of probability sampling across all participating countries. Nonetheless, it is also important to take into consideration that the timing of fieldwork in wave 1 differed considerably between countries - this was related to constraints in each specific country. This information is relevant for data users as the differences between countries might, to some extent, be related to time-specific contextual elements. However, the survey is designed to examine retrospective and within person life-course dynamics, which reduces the need for strict comparability between countries in the timing of fieldwork. It is however an important point for researchers using the data to take note of.
On what concerns the modes of data collection, there is also some diversity in wave 1: Austria, Belgium, France and Germany opted for computerassisted personal interviewing (CAPI), while eastern and southern European countries implemented PAPI (paper and pencil interviewing). In five other countries a mixed-methods strategy was used Australia (PAPI, self-administered paper questionnaire (SAPQ)), Estonia (PAPI, SAPQ), the Netherlands (CAPI, SAPQ), Norway (CATI, SAPQ), Sweden (CATI, SAPQ). In the majority of the countries - with the exception of Austria ${ }^{8}$ and Italy - a pilot survey was used to test fieldwork procedures and the questionnaire.

Fokkema et al. (2016) studied the average interview length in wave 1 and found large variations across countries: Sweden with 26 minutes $^{9}$ to the Russian Federation with 72 minutes - these differences across countries seem to be associated with the survey mode(s) used (countries using CAPI had shorter average interview length); additionally, some countries included some optional sub-modules or added country-specific questions. In wave 2 and 3, most countries continued to use similar survey modes, with PAPI and CAPI prevailing as the most used survey modes.

Regarding the number of contact attempts, in general at least three attempts were made to contact respondents. The minimum number of contact attempts varied according to the contact method used (with more attempts done via telephone than visits to the addresses).

Furthermore, in some countries it was possible to link administrative records with each survey respondent, dependent on the respondent's consent. Benefiting from the fact that Sweden has a central population register, the full sample of the Swedish GGS was linked to a wide range of administrative records before the fieldwork process (carried out by Stockholm University in collaboration with Statistics Sweden) - participation in the survey was dependent on respondent's consent to record linkage. In fact, this strategy allowed also for administrative data validation "this basis of linkage consent enabled the fieldwork to pre-load administrative records [...] enabling respondents the opportunity to correct the data where they deemed necessary" (Emery, 2016, p. 6) - as an example, $18.3 \%$ of the respondents corrected the educational level information interview. 
Table 1. Main fieldwork characteristics of the Generations and Gender Survey round 1

\begin{tabular}{|c|c|c|c|c|c|c|c|}
\hline & & Response & Mode & \multicolumn{4}{|c|}{ Data collection } \\
\hline & & \multirow[t]{2}{*}{$\%$} & & \multicolumn{2}{|l|}{ Wave 1} & \multicolumn{2}{|l|}{ Wave 2} \\
\hline & & & & Start & End & Start & End \\
\hline Australia & 13,571 & 52.5 & $\begin{array}{l}\text { PAPI or Phone, } \\
\text { SAPQ }\end{array}$ & Aug-05 & Mar-06 & Aug-08 & Feb-09 \\
\hline Austria & 9,006 & 61.3 & CAPI & Sep-08 & Feb-09 & Sep-08 & Feb-09 \\
\hline Belgium & 17,836 & 41.8 & CAPI & Feb-08 & May-10 & - & - \\
\hline Bulgaria & 18,591 & 74.8 & PAPI & Nov-04 & Jan-05 & Apr-07 & Jun-06 \\
\hline $\begin{array}{l}\text { Czech } \\
\text { Republic }\end{array}$ & 23,824 & 49.1 & PAPI & Feb-05 & Sep-05 & Jan-08 & Mar-09 \\
\hline Estonia & 11,192 & 70.2 & PAPI, SAPQ & Sep-04 & Dec-05 & Jan-08 & Mar-09 \\
\hline France & 18,009 & 65.2 & CAPI & Sep-05 & Dec-05 & Oct-08 & Dec-08 \\
\hline Georgia & 14,000 & 71.5 & PAPI & Mar-06 & May-06 & Apr-09 & Jun-09 \\
\hline Germany & 20,623 & 55.4 & CAPI & Feb-05 & May-05 & Sep-08 & Mar-09 \\
\hline Hungary & 24,138 & 83.7 & PAPI & Nov-04 & Jan-05 & Nov-08 & Feb-09 \\
\hline Italy & 20,787 & 19.1 & PAPI & Nov-03 & Jan-04 & Feb-07 & Mar-07 \\
\hline Lithuania & 29,884 & 35.6 & PAPI & Apr-06 & Dec-06 & Jun-09 & Dec-09 \\
\hline $\begin{array}{l}\text { The } \\
\text { Netherlands }\end{array}$ & 24,425 & 44.6 & CAPI, SAPQ & Oct-02 & Jan-04 & Sep-06 & Jun-07 \\
\hline Norway & 25,848 & 60.2 & $\begin{array}{l}\text { CATI, SAPQ, } \\
\text { Register }\end{array}$ & Jan-07 & Sep-08 & - & - \\
\hline Poland & 20,000 & 33.3 & PAPI & Oct-10 & Feb-11 & Sep-14 & Jan-15 \\
\hline Romania & 14,280 & 83.9 & PAPI & Nov-05 & Dec-05 & - & - \\
\hline Russian Fed. & 27,089 & 44.8 & PAPI & Jun-04 & Aug-04 & 2007 & 2007 \\
\hline Sweden & 18,000 & 54.7 & $\begin{array}{l}\text { CATI, SAPQ, } \\
\text { Register }\end{array}$ & Apr-12 & Apr-13 & - & - \\
\hline $\begin{array}{l}\text { Germany - } \\
\text { Turkish } \\
\text { subsample }\end{array}$ & 13,890 & 34.5 & CAPI & May-06 & Nov-16 & Sep-09 & Feb-10 \\
\hline
\end{tabular}

Note: Adapted from Fokkema et al. (2016). In this table, wave 3 data is not documented because the data is not yet harmonised and not publicly available. Wave 3 was carried out in five countries: Australia, France, the Netherlands, Hungary and Russian Federation. Information about GGS Belarus and GGS Kazhakstan is beyond the scope of this work as these are part of the new round of data collection (GGP 2020). 
In Norway, the personal interviews were linked with administrative register data that was used as a data source, with the aim to reduce interview length, fieldwork costs and improve data accuracy. Administrative records were also used in the preparation of the sampling frame and for data quality control purposes. Before the interview, the personal identification number was collected and, for several of the survey questions, the information was collected via the administrative records (Lappegård \& Veenstra, 2010). This data linkage allowed for the continuous update of the information after the interview on a number of key topics: births, marital history, migration history, parental leave, income and wealth, educational activity and attainment, and social benefits. An additional advantage was the use of the administrative records information to add rigorous information about the distances between the addresses of family members.

\section{Panel maintenance}

The GGP has, since the first wave, devoted efforts to minimise attrition and has put forward some recommendations for fieldwork practices: continuous and close co-operation between the research institute, the fieldwork agency, the interviewers and the respondents; incentives for respondents that can vary across countries; regular contact with respondents through letters, information brochures, requests for updated contact information, and where feasible, the collection of annual information via a short questionnaire; where possible, interviewer continuity is recommended to help establish a rapport between the respondents and fieldwork staff; and specialised interviewer training and supervision is essential (UNECE, 2005).

In the GGS, the challenge is to be able to trace and contact all respondents after three years (the time between GGS waves), which requires measures to trace and motivate respondents in the period in-between waves. Achieving high response rates and low levels of attrition is a big challenge for social science research infrastructures. In fact, "high nonresponse rates pose a major threat to survey quality as they can cause unwanted systematic deviations from the true outcome of a survey" (Stoop, 2005, p. 5).

Focusing now on specific countries, in Austria the attrition level between the first two waves was $22 \%$. Bubber-Ennser (2014) studied the causes of attrition and concluded that it was affected by "a small bias towards family-oriented persons as well as less-educated respondents and persons with migration background" (p. 460), however this deviation does not affect the reliability of the data.

Among the procedures used for tracing respondents between waves in Austria, central register data was used to track any residential moves. Given that Austrian legislation requires that individuals notify the authorities about any residential move, the central register is continually updated. This way, if respondents moved between wave 1 and 2, the contact address in the register was updated (attrition due to unknown address was expected to be comparatively low) - it was crucial for panel maintenance that Statistics Austria had access to the central register. In order to maintain contact and motivate respondents, postcards were sent to respondents with details about the study and findings. Before the second wave, respondents received an invitation letter with general information about the study and were referred to the Austrian GGS webpage for more information (including the results of the first wave). The matching of respondents and interviewers by gender was another measure adopted to facilitate communication and survey participation.

The attrition levels between the first two waves varied between countries with different factors affecting panel maintenance: in Lithuania the level of attrition was $77.1 \%$; in Czech Republic $68 \%$; in Germany 67\%; in France 35\%; in Bulgaria 27.3\%; in the Netherlands 25.4\%; and in Georgia $17 \%$.

In France, the cumulative attrition after three waves of the survey was $43 \%$ (the highest attrition was registered between wave 1 and 2: 35\%; and $17 \%$ between wave 2 and 3). According to RégnierLoilier and Guisse, this decline in attrition can be attributed to the fact that "the people uninterested in the study or who found the questions too intrusive left at the end of the first wave" (2012, p. 12). In terms of socio-demographic characteristics, these authors found a significant effect of gender, age, education level and nationality on attrition. In the next section, we turn to the data adjustments available in the GGS.

\section{Data adjustment}

In the context of data management, a number of data adjustment procedures are necessary to produce comparable, representative data. This is because there are a number of issues that usually 
bias representation, namely, unequal probabilities of selection, coverage rates and nonresponse. A commonly used solution is the construction of weighting variables, which are used to compensate for factors that can make the data collected unrepresentative of the population.

In wave 1 and 2, most GGS countries designed and provided their own country-specific poststratification weights, with the exception of Bulgaria, Czech Republic, Poland, Romania, and Italy. The weighting factors used for the construction of the weights varied between countries, but the most consistently used were age, gender and region or urbanisation (these data is available in most countries and these are key indicators for researchers).

Fokkema et al. (2016) analysed the representativeness of the wave 1 data - taking into account age, gender, region, marital status, household size and educational level - and concluded that the unweighted data included some bias. However, "when the data were weighted (...) biases for age, gender, region, and household size were substantially lower" (p. 521). Therefore, given the recurrent issues with the representativeness of survey microdata, data users are advised to apply the weights provided ('aweight' in wave 1 and 'bweight' in wave 2).

Data quality is a priority for any GGP outputs and, ahead of any GGS data release, the preharmonised data submitted by national teams is prepared and processed. The main goal is to achieve a clear and comparable format for microdata files that is suitable for cross-national comparison.

The harmonisation procedure involves a number of checks and edits, including i) label checks: ensuring that variable names and values labels are consistent across GGS datasets; ii) table harmonisation: tables need to be harmonised according to the ordering criteria for table-rows; iii) routing: in order to ensure that the data matches the underlying structure of the questionnaire; iv) consolidation: the goal is to compile the information scattered across several variables (this is carried out in the Children, Partnership, Parent and Parental Home sections); v) calculation of derived variables: in order to organise the information available, a number of variables are derived from the grid variables (household, children and partnership), month and year, and frequency and unit variables.

\section{Coverage}

The GGS data covers a wide range of topics and focus on fertility and partnership histories, gender relations, division of housework, work-family balance, transition to adulthood, intergenerational exchanges, economic activity, retirement, health and well-being. The GGS adopts a life course approach and collects both retrospective information (fertility, family formation and dissolution) and intentions (intentions to have children, intentions of union formation, are examples of prospective questions) ${ }^{10}$. The selection of the themes included in the questionnaire follows theoretically grounded criteria, described by Vikat et al. (2007).

Until now, the GGS has been used extensively both in the population studies community and by users across multiple scientific disciplines. The data has been used in a number of international research projects, and master and doctoral theses.

Furthermore, a recent study by Zimmermann and Konietzka (2018) illustrates the potential of GGS data for cross-national research. This work investigates how family life course patterns vary (and become more destandardised) across individuals according to their levels of educational attainment in seven European countries. The authors find that across cohorts, "family life courses have become more destandardized among the lower than the higher educated in all countries except Germany" (p. 71). 
Table 2. Information collected in the GGS

\begin{tabular}{|c|c|}
\hline Questionnaire modules & Examples \\
\hline Household & $\begin{array}{l}\text { Household roster; nationality and ethnicity; dwelling unit; } \\
\text { building, occupancy; problems and satisfaction with the } \\
\text { accommodation; education }\end{array}$ \\
\hline Children & $\begin{array}{l}\text { Childcare; non-resident children; step children; grandchildren; } \\
\text { consolidated children information; complete childbearing } \\
\text { history by month; total number of children }\end{array}$ \\
\hline Partnership & $\begin{array}{l}\text { Current co-resident partner or spouse; current non-resident } \\
\text { partner or spouse; intentions of union formation; complete } \\
\text { partnership history by month; child alimony/ maintenance; } \\
\text { partner alimony }\end{array}$ \\
\hline $\begin{array}{l}\text { Household organisation and } \\
\text { partnership quality }\end{array}$ & Household organisation; decision-making; partnership quality \\
\hline Parent and parental home & $\begin{array}{l}\text { Co-residence with biological parents; questions about biological } \\
\text { parents; brothers, sisters, grandparents; parental home during } \\
\text { childhood; intentions to start living separately from parents }\end{array}$ \\
\hline Fertility & $\begin{array}{l}\text { Ever had sexual intercourse; current pregnancy; fecundity; } \\
\text { intentions to have children }\end{array}$ \\
\hline Health and well-being & $\begin{array}{l}\text { Health in general; personal care; emotional support; locus of } \\
\text { control; well-being }\end{array}$ \\
\hline Respondent's activity and income & $\begin{array}{l}\text { Current activity status; additional job or business; working } \\
\text { conditions and availability of reconciliation policies; income } \\
\text { from work, benefits and other sources }\end{array}$ \\
\hline $\begin{array}{l}\text { Household possessions, income } \\
\text { and transfers }\end{array}$ & $\begin{array}{l}\text { Household possessions and economic deprivation; income from } \\
\text { other sources than employment; total household income; } \\
\text { monetary transfers and inheritance }\end{array}$ \\
\hline Value orientations and attitudes & $\begin{array}{l}\text { Religiosity; attitudes about interpersonal trust; attitudes about } \\
\text { marriage }\end{array}$ \\
\hline Additions in Wave 2 & $\begin{array}{l}\text { Complete activity and education history (working status by } \\
\text { month; highest level of education reached; full- or part-time } \\
\text { employment) }\end{array}$ \\
\hline
\end{tabular}

Note: Additional information about each module and variables is available in the Data Documentation section of the GGP webpage: http://www.ggp-i.org/data/methodology/

\section{Organisation}

A number of national and international institutions participate and support the GGP Research Infrastructure, including research institutes in population studies, governmental demographic research units and universities. Currently, this governance and management structure is being evaluated in the context of the GGP-EPI (Evaluate, Plan, Initiate) project and work is being done to prepare the Research Infrastructure for inclusion on the ESFRI European Strategy Forum on Research Infrastructures (ESFRI) Roadmap.

In terms of data collection, the national teams usually composed by central statistical offices, research institutes and governmental agencies - manage the fieldwork and provide the anonymised microdata along with documentation for all survey instruments. They also enter into a legally binding agreement with the GGP that allows dissemination of the national data by the GGP. Data release agreements have been signed between the UNECE and all countries submitting data.

In terms of data access, through the GGP webpage, it is possible to browse and explore the data (via http://www.ggp-i.org/data/browse-thedata/) and perform basic descriptive analyses. Researchers interested in downloading the data need to sign and submit a statement of affiliation, confidentiality and acceptable usage. The UNECE revises and makes the final decision on user 
accreditation: when the user is granted data access, the data can be downloaded directly from the user account.

\section{Outputs}

On what concerns outputs, the GGP has a set of online products available, including data documentation - core and national questionnaires, guidelines - codebooks (for wave 1 and wave 2), sampling information and country-specific documentation. An important online resource is the NESSTAR data interface that provides direct access to GGS data and metadata, allowing also for simple descriptive analysis (the User Guide is available online). The codebooks contain particularly useful information on variable coding and country specificities. This way, all those interested in the GGS data can easily find all the relevant details about data collection, preparation and harmonisation procedures. The GGP also provides aggregate level data - demographic, economic and policy indicators - through the Contextual Database, which can be linked with the microdata. The Contextual Database includes information for 60 countries on more than 100 indicators.

A selection of technical papers is also available covering technical aspects of the GGP: attrition, sampling, fieldwork methods, response rates, and non-response, among other issues. Moreover, some of these papers explore specific national contexts: for example, Régnier-Loilier and Guisse (2012) studied sample attrition and distortion on the French GGS, while Vanderschrick and Sanderson (2012) analysed item non-response in the Belgium GGS. In addition, the GGP website includes a list of hundreds of scientific publications available, based on GGS data.

\section{Evaluation and concluding remarks}

Evaluating the Generations and Gender Survey is not an easy exercise. The GGS has unique characteristics and has faced a number of challenges during its existence. In this final section, we start with an overview of the main strengths and weaknesses of the GGS and conclude with a brief outline of the strategy and objectives for the future of the infrastructure.

The GGS has achieved impressive results and made important contributions as a unique longitudinal data resource on families and life course trajectories, shaping to large extent the research agenda in the field. This is in large part due to the theory-driven and multidisciplinary questionnaire, panel design and large sample sizes that are key features of the GGS. Due to its complex structure and numerous constraints, the GGS has faced a number of challenges and problems in the past. First, given the decentralised structure of the GGP and difficulty in enforcing centralised guidelines, there were issues with the modifications introduced by national teams in the questionnaires fielded, which in turn affected negatively the comparability of the data collected. For example, the reference periods for support in Italy were adjusted from one year to four weeks for reasons of national level comparability. In addition, these deviations also contributed to the slow data cleaning and processing that involved timeconsuming post-hoc data harmonisation activities. All these deviations are however clearly documented in the online codebook available via NESSTAR.

One other issue concerns the levels of attrition that also affect a vast number of longitudinal studies - and the difficulties encountered in tracing and motivating panel members. Furthermore, the GGS is not immune to the difficulties that most social science research infrastructures face, namely problems in accessing sustainable funding and raising fieldwork costs. All these issues demand close attention and an effective strategy for tackling these challenges.

One area in which the GGP has been able to advance the incorporation of innovations in surveys concerns the use of administrative records in the survey process. Administrative data can contribute to reducing the burden on survey respondents, which represents an important goal in social science research, not only due to the rising costs of survey data collection, but also because administrative records can potentially provide a more comprehensive picture in certain domains (for example, tax records or social security payments data). Nonetheless, statistical disclosure concerns and data privacy legislation have been at the forefront of the arguments advanced by the data owners/ custodians - typically national statistical offices - to restrict and control the usage of administrative data.

In preparation for the next round of data collection, planned for early 2020, an experimental study on fieldwork strategies is being designed to test the implementation of a mixed-mode strategy 
of data collection ('push to web' approach) in three national contexts - Croatia, Germany and Portugal - the idea is that these countries represent much of the diversity of European countries, including also in terms of the availability of central register data for drawing samples and fieldwork costs. This work is being conducted in the context of the GGP-EPI project, which is funded by a $€ 2$ million grant ( $n$. 739511) by the European Commission. The project has three main objectives: to evaluate the current executive and operational structures of the GGP and assess alternative models; to identify the best model of operations for the GGP's future; and to develop the required legal, technical and financial arrangements necessary for the next phase.
This experimental study will also allow for the testing of a more centralised and standardised model of data collection and management. In each country an additional experiment will be conducted to evaluate a number of fieldwork specifications: in Germany, different strategies for providing incentives will be tested; in Croatia, different strategies for sending out reminders will be evaluated; and in Portugal, different strategies for delivering the incentive to the selected respondent will be assessed. Part of the vision and ambition for the next round will involve improvements in all stages of the survey in order to achieve higher efficiency, lower fieldwork costs, quicker data processing and better microdata.

\section{Acknowledgements}

The GGP is partly funded by the European Union's Horizon 2020 Research and Innovation Programme under grant agreement no. 739511 for the project Generations and Gender Programme: Evaluate, Plan, Initiate.

\section{References}

Azjen, I. (1991). The theory of planned behavior. Organizational Behavior and Human Decision Processes, 50, 179-211. https://doi.org/10.1016/0749-5978(91)90020-T

Bubber-Ennser, I. (2014). Attrition in the Austrian Generations and Gender Survey: Is there a bias by fertilityrelevant aspects? Demographic Research, 31, 459-496. https://doi.org/10.4054/DemRes.2014.31.16

Emery, T. (2016). Administrative data linking: enriching administrative data with surveys. Paper presented at the European Conference on Quality in Official Statistics, 31 May-3 June 2016, Madrid.

Fokkema, T., Kveder, A., Hiekel, N., Emery, T., \& Liefbroer, A. (2016). Generations and Gender Programme Wave 1 data collection: an overview and assessment of sampling and fieldwork methods, weighting procedures, and cross-sectional representativeness. Demographic Research, 34, 499-524. https://doi.org/10.4054/DemRes.2016.34.18

Gauthier, A., \& Emery, E. (2014). Generations and Gender Programme: A Research Infrastructure for Analysing Relationships over the Life-Course. In A. Duşa, D. Nelle, G. Stock, \& G. Wagner (Eds.), Facing the Future: European Research Infrastructures for the Humanities and Social Sciences (pp. 99108). Berlin: SCIVERO Verlag.

Lappegård, T., \& Veenstra, M. (2010). Life-course, generation and gender. LOGG 2007. Field Report of the Norwegian Generations and Gender Survey. Oslo: Statistics Norway. Accessed 29th November 2017 from ggpsurvey.ined.fr/documents/Questionnaires/Norway_FieldReport\&Questionnaire_W1_en.pdf

Régnier-Loilier, A., \& Guisse, N. (2012). Sample attrition and distortion over the waves of the French Generations and Gender Survey, GGP Technical Paper. Accessed 30th October 2017 from http://www.ggp-i.org/sites/default/files/technicalpapers/Regnier-Lollier_and_Guisse__Sample_attrition_and_distortion_over_the_waves.pdf

Simard, M., \& Franklin, S. (2005). Sample design guidelines. In United Nations Economic Commission for Europe (ed.). Generations and Gender Programme. Survey Instruments (pp. 3-14). New York and Geneva: United Nations.

Stoop, I. (2005). The Hunt for the Last Respondent. The Hague: Social and Cultural Planning Office of the Netherlands.

UNECE (2005). Generations and Gender Programme. Survey Instruments. New York and Geneva: United Nations. 
Vandeschrick, C., \& Sanderson, J. (2012). GGS Wave 1 Belgium: Item non-response. GGP Belgium Paper Series n. 5. Accessed 7th October 2017 from http://www.ggps.be/doc/GGP_Belgium_Paper_Series_5.pdf

Vikat, A., Spéder, Z., Beets, G., Billari, F., Bühler, C., Désesquelles, A., Fokkema, T., Hoem, J., MacDonald, A., Neyer, G., Pailhé, A., Pinnelli, A., \& Solaz, A. (2007). Generations and Gender Survey (GGS): towards a better understanding of relationships and processes in the life course. Demographic Research, 17, 389-440. https://doi.org/10.4054/DemRes.2007.17.14

Wolf, K. (2014). Fertility of Turkish migrants in Germany: duration of stay matters. MPIDR Working paper WP2014-001. Accessed 20th October 2017 from http://www.demogr.mpg.de/papers/working/wp2014-001.pdf.

Zimmermann, O. \& Konietzka, D. (2018). Social disparities in destandardization - changing family life course patterns in seven European countries. European Sociological Review, 34(1), 64-78. https://doi.org/10.1093/esr/jcx083

\section{Endnotes}

1. Data for Australia originates from the 'Household, Income and Labour Dynamics in Australia Survey'.

2. The GGS Belarus data was collected in 2017 and this is the first country to take part in the new round of data collection (GGP 2020).

3. Data for Italy originates from 'Famiglia e soggetti sociali (FSS)' in wave 1 and 'Criticità dei percorsi lavorativi in un'ottica di genere' in wave 2.

4. Data for Japan originates from the 'International Comparative Survey on Marriage and the Family'.

5. The GGS Kazakhstan data was collected recently in 2018 and this is the second country to take part in the new round of data collection (GGP 2020).

6. Data for the Netherlands originates from the 'Netherlands Kinship Panel Study' and more recently from the 'Onderzoek Gezinsvorming'.

7. Details on unit selection available via 'Metadata' in the GGP NESSTAR webpage. The methods used were random number generator (Austria and Estonia), last birthday method (Lithuania and Poland), next birthday method (the Netherlands), first-name method - among those eligible in the household, the person whose first name begins with the letter closest to the beginning of the alphabet was selected (France), Kish tables (Germany, Romania and Russian Federation).

8. In the case of Austria, a pilot study was not conducted because the same questionnaire had already been used in Germany.

9. The interview length in Sweden was shorter because participation in the survey required respondents' consent to linkage with administrative data records (since the information was pre-loaded for some answers, this reduced the amount of questions asked).

10. Parts of the questionnaire were inspired in the Theory of Planned Behaviour (Azjen, 1991). 